\title{
Prognostic Factors and Treatment Outcome in 178 Locally Advanced Cervical Cancer Patients
}

\author{
Ozlem Yetmen Dogan ${ }^{1 *}$, Makbule Dogan Eren ${ }^{1}$, Sedef Ozdemir Dag², Alparsalan Mayadağli ${ }^{3}$ \\ ${ }^{1}$ Radiation Oncology Department, Kartal Dr Lutfi Kurdar Training and Research Hospital, Saglik Bilimleri University, Istanbul, Turkey \\ ${ }^{2}$ Radiation Oncology Department, Sisli Hamidiye Etfal Training and Research Hospital, Istanbul, Turkey \\ ${ }^{3}$ Radiation Oncology Department, Bezmialem Vakıf University, Istanbul, Turkey \\ Email: *dryetmen@gmail.com
}

How to cite this paper: Dogan, O.Y., Eren, M.D., Dag, S.O. and Mayadağli, A. (2018) Prognostic Factors and Treatment Outcome in 178 Locally Advanced Cervical Cancer Patients. Open Journal of Obstetrics and Gynecology, 8, 485-496.

https://doi.org/10.4236/ojog.2018.85055

Received: March 14, 2018

Accepted: May 11, 2018

Published: May 14, 2018

Copyright (C) 2018 by authors and Scientific Research Publishing Inc. This work is licensed under the Creative Commons Attribution International License (CC BY 4.0).

http://creativecommons.org/licenses/by/4.0/

\begin{abstract}
Background: To evaluate local control, survival, radiation side effects and treatment outcome in locally advanced cervical cancer patients. Materials and Methods: Among 2006-2011, 178 patients with locally advanced cervical cancer were treated with chemoradiotherapy $+/$ - radiotherapy and high dose rate (HDR) brachytherapy. Follow-up was complete for all patients. Concomitant chemotherapy was not administered in 44 patients due to renal impairments and ECOG of 2 - 3. Results: The median follow-up period was 34.5 months (range, 5 to 93) and 42 months (range, 14 to 93 months) for alive patients. Five years local-regional control, progression-free survival and overall survival rates were $87.8 \%, 58.9 \%$ and $67.3 \%$ in all patients, respectively. In this retrospective study young age, tumor diameter, stage, presence of residual tumor and administration of chemotherapy were effected in survival analysis. The parameters which affected the complete response of patients were defined as presence of concomitant chemotherapy and number of courses $<5$. Central region recurrence rate was defined higher in the group with treatment duration of 9 weeks and higher $(p=0.044)$. Conclusion: Primary chemoradiotherapy $+/$ - radiotherapy achieved a satisfactory rate of local control and survival rates with acceptable complications in locally advanced cervical cancer. Concomitant chemotherapy and treatment duration were the important prognostic factors for completed response locally advanced cervical cancers.
\end{abstract}

\section{Keywords}

Locally Advanced Cervix Cancer, Chemo-Radiotherapy, Cervix Cancer

\section{Introduction}

Cervical cancer is among the cancers, in which the mortality rates are decreased 
as the result of intense studies on its diagnosis and treatment [1]. The most important prognostic factors for cervical cancer have been defined as the stage, cell type, lesion size, presence of deep invasion, lymphovascular invasion and regional lymph node involvement. Lymph node involvement is the most important among these factors. Surgery or radiotherapy provides the recovery rate of $90 \%-95 \%$ in the early disease. The primary treatment of locally advanced cervical cancer is the radical radiotherapy applied concomitantly with cisplatin based chemotherapy. The control rates of large tumors are increased by the use of brachytherapy in the cervical cancer [2] [3].

In the five randomized, phase III studies published until February 1999, the general survival rate was increased by $30 \%$ and the toxicity was reported within the accepted limits by the help of cisplatinium based chemotherapy concomitantly administered with radiotherapy [4] [5] [6] [7] [8]. Although there were differences in the stage, radiotherapy dose, radiotherapy and cisplatin administration protocols between the studies, the statistically significant increase in the survival rate was observed in five studies with concomitant administration of radiotherapy and chemotherapy. According to the obtained results, it is accepted currently that concomitant administration of cisplatinium based chemotherapy is the standard treatment in cervical cancer patients who are being treated by radiotherapy [9] [10].

In this retrospective study, we evaluate the long term follow up for locally advanced cervical cancer who had chemo-radiotherapy in our hospital. In the literature there are a lot of factors in the treatment for locally advanced cervical cancer, in that study we searched the prognostic factors for treatment. This study shows that prognostic factors, which are tumor size, age, presence of residual tumor, number of chemotherapy treatments, are important for treatment options. A total of 178 patients with FIGO Stage IB2-IV cervical cancer, who applied to the Radiation Oncology Clinic at the Dr. Lutfi Kırdar Kartal Research and Training Hospital between years 2006 and 2011, and received radiotherapy and/or concomitant chemotherapy, were evaluated.

\section{Material Method}

In this present study, our gynecology oncology clinic evaluate all the patients every week for treatment options. That clinic refers locally advanced cervical cancer patients to our radiation department for treatment.178 patients with locally advanced cervical cancer, who applied to the Radiation Oncology Clinic at the Dr. Lutfi Kirdar Kartal Research and Training Hospital between January 2006 and December 2011, and received radiotherapy or chemoradiotherapy treatments with complete follow ups, were retrospectively investigated.

FIGO (International Federation of Gynecology and Obstetrics) 2009 system was used for the staging. Patients who were treated before that date were re-staged according to this staging system. Anamnesis, systemic and gynecological examinations, whole blood count, biochemistry and PA chest radiographic 
examinations were performed in all patients. Although clinical staging was performed, MRI and PET-CT were used for the staging. Rectoscopy and cystoscopy were performed in patients with the suspect of rectum or bladder involvement. Patient characteristics are summarized in Table 1.

Table 1. Patients characteristics.

\begin{tabular}{|c|c|c|c|c|}
\hline & \multicolumn{2}{|c|}{ RADIOTHERAPY } & \multicolumn{2}{|c|}{ CHEMO-RADIOTHERAPY } \\
\hline & $\mathrm{N}(44)$ & $24.7 \%$ & $\mathrm{~N}(134)$ & $75.3 \%$ \\
\hline \multicolumn{5}{|l|}{ Age } \\
\hline$\leq 60$ & 25 & 56.8 & 97 & 72.4 \\
\hline $60<$ & 19 & 43.2 & 37 & 27.6 \\
\hline \multicolumn{5}{|l|}{ Histology } \\
\hline Squmous & 40 & 90.9 & 119 & 88.8 \\
\hline Adenocarsinoma & 4 & 9.1 & 9 & 6.7 \\
\hline Adenosquamous & - & - & 3 & 2.2 \\
\hline Others & - & - & 3 & 2.3 \\
\hline \multicolumn{5}{|l|}{ Stage } \\
\hline IB2 & 3 & 6.8 & 6 & 4.5 \\
\hline IIA & 3 & 6.8 & 9 & 6.7 \\
\hline IIB & 25 & 56.8 & 87 & 64.9 \\
\hline IIIA & 3 & 6.8 & 5 & 3.7 \\
\hline IIIB & 6 & 13.6 & 13 & 9.7 \\
\hline IV & 4 & 9.1 & 14 & 10.4 \\
\hline \multicolumn{5}{|l|}{ Tm diameter } \\
\hline$\leq 4 \mathrm{~cm}$ & 14 & 31.8 & 31 & 23.1 \\
\hline$>4 \mathrm{~cm}$ & 30 & 68.2 & 103 & 76.9 \\
\hline \multicolumn{5}{|l|}{ Menapousal status } \\
\hline Pre-menapause & 21 & 47.7 & 57 & 42.5 \\
\hline Post-menapause & 23 & 52.3 & 77 & 57.5 \\
\hline \multicolumn{5}{|l|}{ First symptom } \\
\hline Vaginal bleeding & 28 & 64.6 & 93 & 69.4 \\
\hline Vaginal bleeding + pain & 11 & 25 & 29 & 21.6 \\
\hline Pain & 4 & 9.1 & 8 & 6 \\
\hline Asymptomatic & 1 & 2.3 & 4 & 3 \\
\hline \multicolumn{5}{|l|}{ Nodal status } \\
\hline Nod (-) & 8 & 18.2 & 37 & 27.6 \\
\hline Pelvic nod (+) & 12 & 27.3 & 28 & 20.9 \\
\hline Para-aortic nod $(+)$ & 0 & 0 & 2 & 1.5 \\
\hline Pelvic +para-aortic $(+)$ & 0 & 0 & 3 & 2.2 \\
\hline Unknown & 24 & 54.5 & 64 & 47.8 \\
\hline
\end{tabular}


Conventional or conformal external radiotherapy was administered in the pelvic region with fractions of 1.8 - 2 Gy with a total of 45 - 50.4 Gy. Standard pelvic areas were used as the treatment volumes. Intracavitary treatment was performed in 157 (88.2\%) patients after the external radiotherapy. External boost therapy was administered in $21(11.8 \%)$ patients, who did not have intracavitary treatment. Cisplatin $40 \mathrm{mg} / \mathrm{m}^{2}$ week chemotherapy was administered concomitantly with radiotherapy in 134 patients as the standard regimen. Concomitant chemoradiotherapy was administered with 6 courses in 2 (1.5\%) patients; with 5 courses in $78(43.8 \%)$ patients; with 4 courses in 51 (28.7\%) patients; with 3 courses in 2 (1.1\%) patients; and 2 courses in $1(0.6 \%)$ patient. Concomitant chemotherapy was not administered in 44 patients because they had renal impairments and/or ECOG of 2 - 3.

Among patients with adequate responses to the external radiotherapy, the point A was administered in 87 patients with 4 fractions of $26 \mathrm{~Gy}$; in 40 patients with 3 fractions of $21 \mathrm{~Gy}$; in 16 patients with 5 fractions of $27.5 \mathrm{~Gy}$; in 5 patients with 4 fractions of $24 \mathrm{~Gy}$; in 3 patients with 3 fractions of $18 \mathrm{~Gy}$; in 3 patients with 5 fractions of $30 \mathrm{~Gy}$; and in 3 patients with 3 fractions of 15 Gy by using intracavitary radiotherapy $\mathrm{Cs}^{137}$ sourced, high velocity rate Curietron device.

Treatment responses (complete response, partial response, stationary disease, and progressive disease) were evaluated according to criteria of the World Health Organization. Early and late side effects were defined according to RTOG/EORTC acute and late radiation morbidity scoring criteria. During the follow up, control was planned in every 3 months in the first year; in every 6 months up to 5 years; and once in a year after the year 5. Gynecological examination and vaginal smear were performed at every control visit. Routine biochemistry teats, chest radiography, and radiological examinations were performed in every 6 months. If there was any suspect of recurrence or metastasis, additional examinations were performed.

SPSS (Statistical Package for the Social Sciences) for Windows 17.0 program was used for statistical analyses. Local-regional control, progression-free survival, and overall survival curves were obtained by using Kaplan-Meier method; log-rank test was used for the significance. Time to progression was noted as recurrence at the time of diagnosis, metastasis or time to death, which was developed due to any reason other than the recurrence. The overall survival was defined as time between the diagnosis and death. Significant factors in the single variable analysis were included in the multiple variable analysis. Chi square test was used for local-regional recurrences, and parameters affecting the distance metastasis and treatment response. Cox regression method was used in the multiple variable analysis.

Age, stage, tumor diameter, tumor response at the end of external pelvic radiation, concomitant chemotherapy and number of courses, menopausal status, local recurrence area, total treatment duration, and external radiotherapy dose were selected as the prognostic factors. Results were accepted significant within the $95 \%$ confidence interval, and at $p<0.05$. 


\section{Results}

Locally advanced cervical cancer patients, who applied to our clinic between the years 2006 and 2011, and had concomitant chemoradiotherapy or radical radiotherapy, were retrospectively evaluated. Median age was 54 (30 - 85) years; the application symptom of majority of our patients was abnormal vaginal bleeding (67.4\%). Patients were followed up with the median of 34.5 (5 - 93) months and 42 (14 - 93) months for alive patients.

When patients were evaluated according to their stages; 9 (5.1\%) were at the stage IB2; $12(6.7 \%)$ were at the stage IIA; $112(62.9 \%)$ were at the stage IIB; 8 (4.5\%) were at the stage IIIA; $19(10.7 \%)$ were at the stage IIIB; and $18(10.1 \%)$ at the stage IV. Majority of our patients had squamous cell carcinoma (89.3\%). Pelvic node involvement was determined in 40 (22.4\%) patients; paraaortic lymph node involvement was observed in $2(1.1 \%)$ patients; and both pelvic and paraaortic lymph nodes were determined in $3(1.6 \%)$ patients.

Median radiotherapy dose was 4600 cGy (range: 4500 - 5040 cGy). During post-radiotherapy or post-chemoradiotherapy evaluations, 146 out of 178 patients (82\%) had complete response, whereas 19 (10.7\%) patients had partial response. During the post-treatment follow up, local recurrence was detected in 17 (9.5\%) patients, and distance metastasis was detected in 49 (27.5\%) patients. The highest rates of distant and regional recurrences were the Stage IIB in those patients.

Two years and 5 years local control rate, progression-free survival, and overall survival were determined as $89 \%$ and $87.8 \% ; 68.4 \%$ and $58.9 \% ; 81.9 \%$ and $67.3 \%$ in all patients, respectively (Figure 1).

In the univariate analysis, young age ( $\leq 60$ years) was affected negative factor for local control in all patients $(p=0.026)$. Tumor diameter over $4 \mathrm{~cm}$ was defined as an unfavorable factor for only progression-free survival $(p=0.021)$. Presence of residual tumor affected the overall, progression-free survival and the local control after the treatment $(p \leq 0.001)$. It was observed that concomitant administration of chemoradiotherapy were favorable factors on the overall and progression-free survivals $(p=0.005)$. Number of chemotherapy courses $<5$ had negative effect on the overall survival, but it was not statistically significant ( $p=$ 0.7) (Table 2).

The parameters which affected the complete response of patients were defined as presence of concomitant chemotherapy and number of courses $<5$ (Table 3 ). Also, when the correlation between treatment duration and local recurrence region was investigated, central region recurrence rate was defined higher in the group with treatment duration of 9 weeks and higher $(p=0.044)$.

In the multivariate analysis performed on all patients, residual tumor presence was defined as an independent prognostic factor affecting the progression-free survival and overall survival. The tumor diameter more than $4 \mathrm{~cm}$ had an unfavorable effect on the progression-free survival and overall survival. Concomitant cisplatin-based chemotherapy administration had favorable effects on progression-free survival and overall survival (Table 4). 

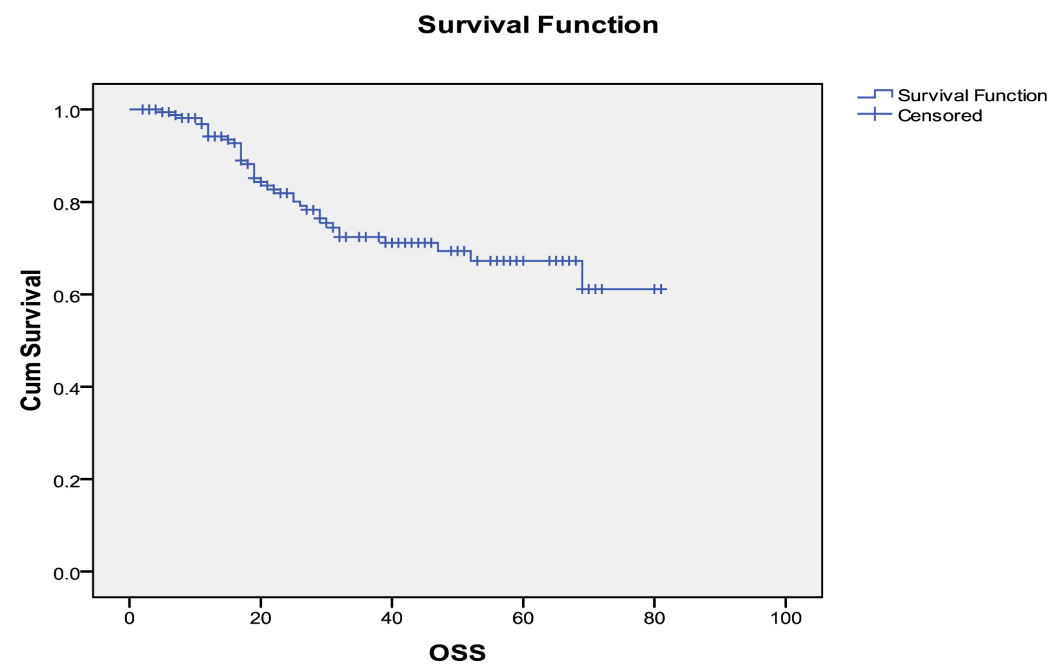

(a)

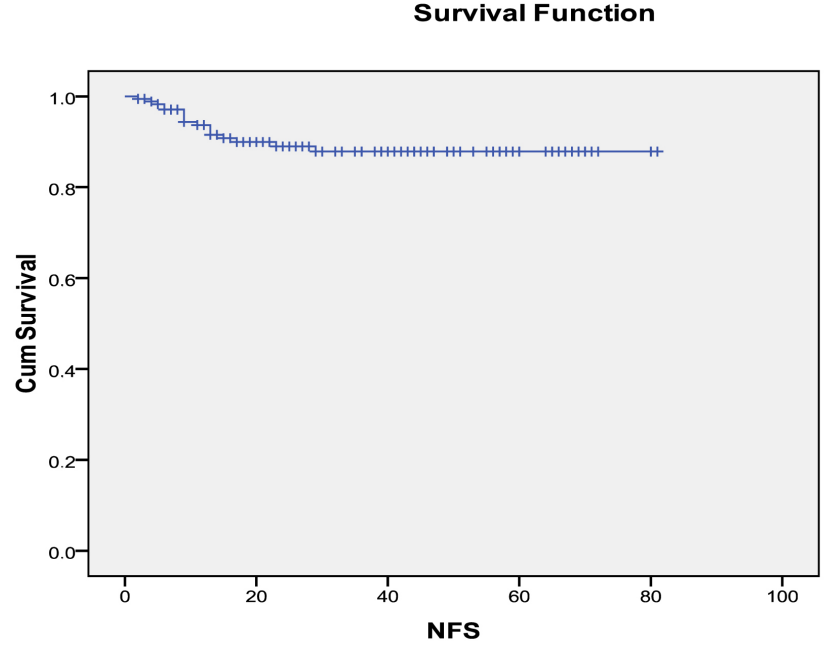

$\neg$ Survival Function + Censored

(b)

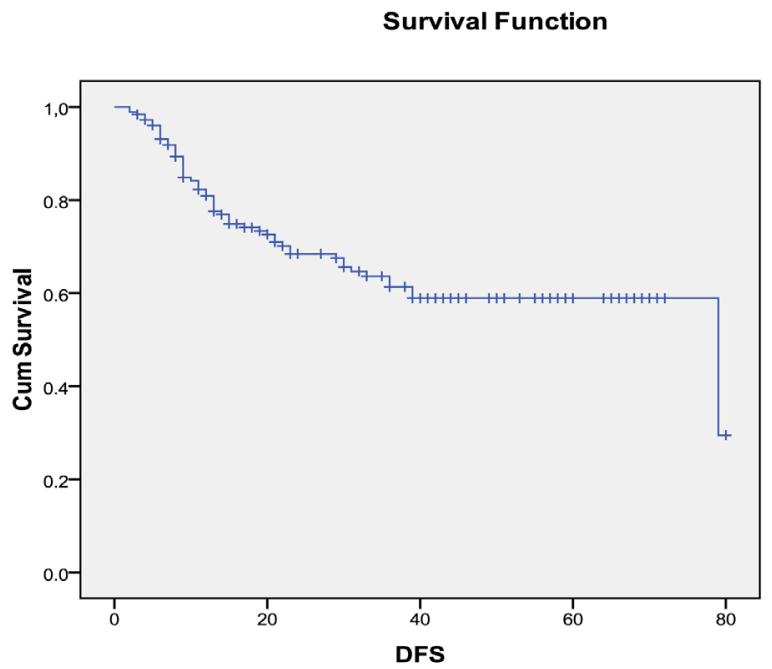

$-\neg$ Survival Function + Censored

(c)

Figure 1. 5 years Overall Survival (OSS), Local Control Rates (NFS), Disease-free Survival (DFS). 
Table 2. Univariate analysis of overall survival, progression free survival and local control rates.

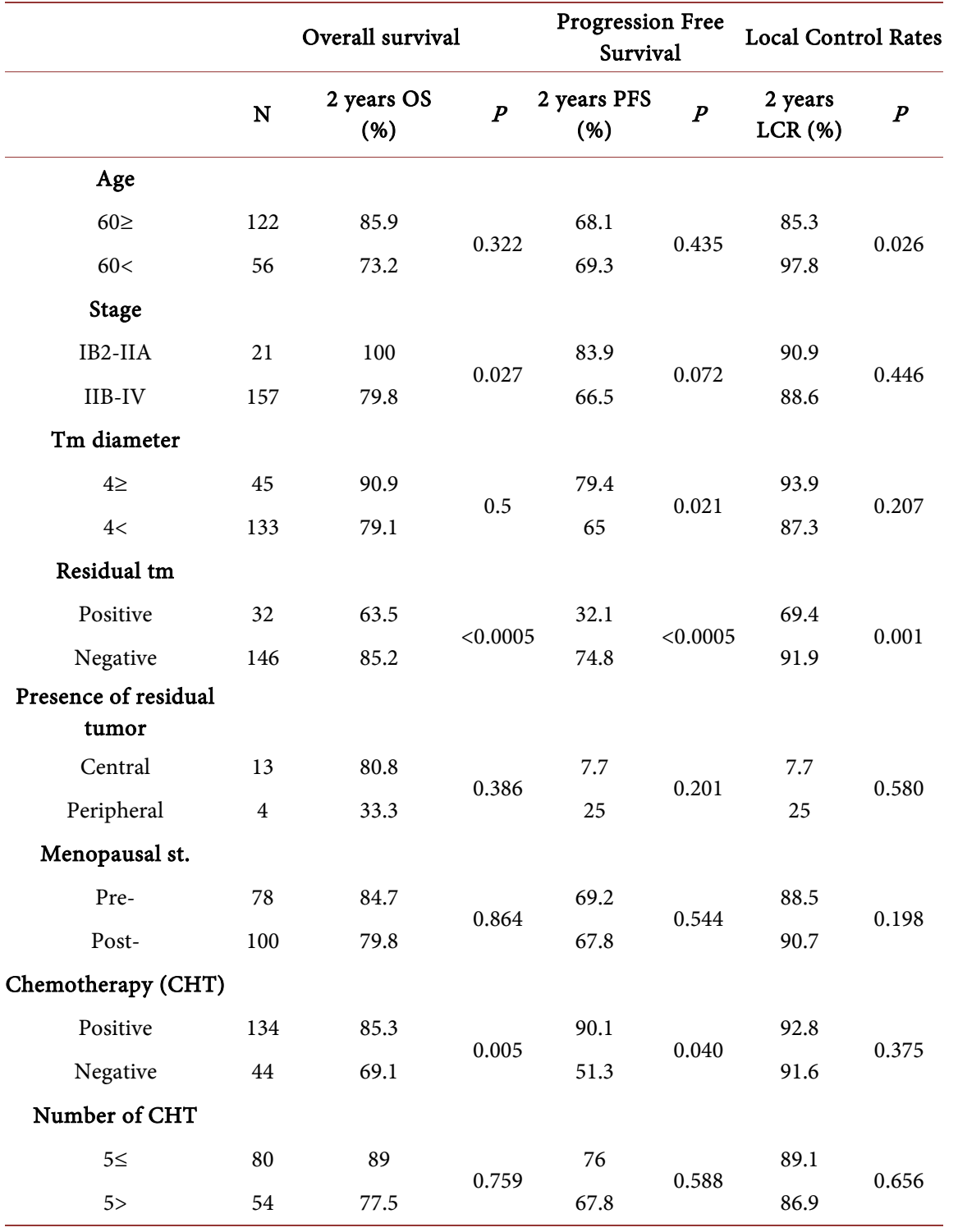

Table 3. The parameters which affected the treatment responses.

\begin{tabular}{cccc}
\hline & $\begin{array}{c}\text { Complete response } \\
\text { (n) }\end{array}$ & $\begin{array}{c}\text { Not-complete response } \\
(\mathrm{n})\end{array}$ & $\boldsymbol{P}$ \\
\hline $\begin{array}{c}\text { Chemotherapy (CHT) } \\
\text { Positive }\end{array}$ & 115 & 19 & 0.039 \\
Negative & 31 & 13 & \\
Tm diameter & 107 & & 0.5 \\
$4 \geq$ & 39 & 26 & \\
$4<$ & & 6 & 0.002 \\
\hline Number of CHT & 75 & 5 & \\
$5 \leq$ & & & \\
\hline
\end{tabular}




\section{Continued}

\begin{tabular}{cccc}
\hline $5>$ & 40 & 14 & \\
$\begin{array}{c}\text { Total treatment time } \\
\text { (EBRT + ICRT) } \\
9 \text { weeks }< \\
8 \text { weeks }>\end{array}$ & 125 & 27 & 0.788 \\
Age & 21 & 5 & \\
$60 \geq$ & 45 & & 0.68 \\
$60<$ & 101 & 11 & \\
Stage & & 21 & 1.000 \\
IB2-IIA & 17 & & \\
IIB-IV & 129 & 4 & \\
\hline
\end{tabular}

Table 4. Multivariate analysis performed on all patients (n: 178).

\begin{tabular}{cccc}
\hline & Local control rates $(\boldsymbol{p})$ & Progression free survival $(\boldsymbol{p})$ & Overall survival $(\boldsymbol{p})$ \\
\hline Age & 0.095 & 0.617 & 0.451 \\
Stage & 0.345 & 0.048 & 0.972 \\
Tumor & 0.554 & 0.041 & 0.057 \\
Residuel & 0.006 & $<0.0005$ & 0.001 \\
Treatment & 0.984 & 0.760 & 0.237 \\
Chemotherapy & 0.687 & 0.039 & 0.002 \\
\hline
\end{tabular}

\section{Side Effects}

The most commonly encountered early side effects in our patients were grade 1 2 cystitis (21.8\%), and grade 1 - 2 diarrhea (11.3\%). No grade IV side effect was observed in any patiens. Side effects were evaluated statistically by using Chi square test, but no significant result was obtained. When the late side effects were evaluated, they were defined as grade 3 proctitis (12.7\%) and grade 3 genitourinary side effects (6\%).

\section{Discussion}

In locally advanced cervical cancer local control rates are $70 \%-90 \%$ in the standard radiotherapy treatment and $2 / 3$ of recurrences are observed within the radiotherapy region [2] [4] [5] [11]. The results of five randomized studies, in which concomitant chemoradiotherapy was administered to increase the efficacy of radiotherapy, were published, and it was shown that chemotherapy administration, especially the cisplatin based chemotherapy, provided survival advantage [4] [5] [6] [7] [8] [12] [13].

It was published in the meta-analysis, which included 18 randomized studies in 2008, that cisplatin-based chemoradiotherapy decreased the local and distant recurrences; and increased progression-free and overall survival more than the 
non-cisplatin based chemoradiotherapy regimens [8]. Gynecological Oncology Group analyzed 642 patients, who had definitive radiotherapy because of locally advanced disease in 3 prospective, clinical trials. The group reported in this multivariate analysis that the most important independent predictor was para-aortic lymph node involvement among other risk factors related to survival and relapse. The most important two prognostic factors were reported as pelvic lymph node involvement and tumor size in cases without para-aortic lymph node involvement. The other weak risk factors were clinical stage, patient age, and performance status. In this analysis, it was shown that cell type, histological grade, pre-treatment hematocrit level, and peritoneal cytology signs did not have any significant prognostic importance in the locally advanced disease.

In the literature, the prevalence of pelvic failure depends on several factors, which according to the studies are age, cancer stage, initial tumor stage, lymph node invasion and residual tumor volume after chemoradiotherapy [14] [15]. The rate of residual cervical tumor after hysterectomy is estimated at $40 \%-50 \%$ [5]-[17]. In a multicenter series of 175 patients who underwent surgery after chemoradiotherapy and brachytherapy for advanced cervical cancer, Classe et al. showed that patients with a complete histological response had a better survival rate at five years than patients who had residual tumor $(88.9 \%$ vs $54.7 \%, p=$ 0.0001) [17]. Houvenaeghel et al. Showed that the presence of residual tumor of the uterine cervix was associated with a higher rate of pelvic lymph node involvement $(p=0.0031)$ and that the rate of pelvic lymph node metastases after chemoradiotherapy was $16 \%$ [18].

In the present study, it was observed that early age onset of the disease had unfavorable effects on local control of the disease in all patients. Tumor size $>4$ $\mathrm{cm}$ had negative effects on the progression-free survival; and Stage IIB-IV of patients had negative effects on the overall survival. It was observed in the post-treatment, control MRI examinations that the presence of residual tumor was a worse prognostic factor for the survival and local-regional control. The pelvic nodal involvement, which was reported among the most important prognostic factors in many studies, was not determined as significant in this present study [19] [20] [21]. It was thought that this was caused because nodal condition of the majority of patients was unknown. Cisplatin is the preferred systemic agent for concomitant use with radiotherapy, because of its low bone marrow toxicity. The leading side effects in concomitant chemoradiotherapy studies were hematological toxicities. As it was in the study of Gynecologic Oncology Group, drug toxicity rates were increased and grade III and IV toxicities might be observed in administrations of two or more drug combinations [22].

In the study by Keys et al. in which 183 cases with Stage IB2 cervical cancer were randomized to radiotherapy only and concomitant cisplatin $\left(40 \mathrm{mg} / \mathrm{m}^{2}\right)$ administration with radiotherapy. The hematological toxicity was determined in 3 cases in the first arm, and 39 cases in the second arm. The gastrointestinal toxicity was determined in 26 cases in the first arm, and in 9 cases in the second 
arm. The genitourinary side effects of grade I and II were determined higher in the combined treatment group, whereas no difference was determined in late side effects between the groups [5]. When this present study is evaluated for side effects, the most commonly encountered side effects were related to the genitourinary system, and there was no difference in late side effects between the groups. The results were similar to toxicity results of the study conducted by Keys et al.

Given its retrospective design, this study has a number of limitations. A multidisciplinary approach to the treatment of cervical cancer has led to marked improvement in outcome. The combination of EBRT and HDR BRT together with concomitant chemotherapy in the treatment of locally advanced carcinoma of cervix is safe and well tolerated with acceptable morbidity.

\section{Conclusion}

This study is prospective and it has limitations but it shows us that prognostic factors for locally advanced cervical cancer are very important. We have to be careful when the patient has young age, more than $4 \mathrm{~cm}$ tumor, presence of residual tumor after treatment and we have to try to give more than 5 times concomitant chemotherapy with radiotherapy. Also pelvic nodal involvement is important factor for cervical cancer treatment but in our study we couldn't determined. Multidisciplinary approach is needed for locally advanced cervical cancer because survival is much better than the other cancer types.

\section{Conflict of Interest}

This article has no conflict of interest.

\section{References}

[1] Makuc, D.M., Freid, V.M. and Kleinman, J.C. (1989) National Trends in the Use of Preventive Health Care by Women. American Journal of Public Health, 79, 21-26. https://doi.org/10.2105/AJPH.79.1.21

[2] Lehman, M. and Thomas, G. (2001) Is Concurrent Chemotherapy the New Standard of Care for Advanced Cervical Cancer. International Journal of Gynecological Cancer, 11, 87-99. https://doi.org/10.1046/j.1525-1438.2001.011002087.x

[3] Robert, K.B., Urdaneta, N., Vera, R., Vera, A., Gutierrez, E., Aguilar, Y., Ott, S., Medina, I., Sempere, P., Rockwell, S., Sartorelli, A.C., Fischer, D.B. and Fischer, J.J. (2000) Interim Results of a Randomized Trial of Mitomycin-C as an Adjunct to Radical Radiotherapy in the Treatment of Locally Advanced Squamoz Cell Carcinoma of the Cervix. International Journal of Cancer, 90, 206-223. https://doi.org/10.1002/1097-0215(20000820)90:4<206::AID-IJC4>3.0.CO;2-O

[4] Rose, P.G., Bundy, B.N., Watkins, E.B., Thigpen, J.T., Deppe, G., Maiman, M.A., Clarke-Pearson, D.L. and Insalaco, S. (1999) Concurrent Cisplatin-Based Radiotherapy and Chemotherapy for Locally Advanced Cervical Cancer. New England Journal of Medicine, 340, 1144-1153. https://doi.org/10.1056/NEJM199904153401502

[5] Keys, H.M., Bundy, B.N., Frederick, B.S., Stehman, F.B., Okagaki, T., Gallup, D.G., Burnett, A.F., Rotman, M.Z. and Fowler Jr., W.C. (1999) Cisplatin, Radiation and 
Adjuvant Histerectomy Compared with Radiation and Adjuvant Hyterectomy for Bulky Stage IB Cervical Carcinoma. New England Journal of Medicine, 340, 1154-1164. https://doi.org/10.1056/NEJM199904153401503

[6] Morris, M., Elfel, P.J., Lu, J., Grigsby, P.W., Levenback, C., Stevens, R.E., Rotman, M., Gershenson, D.M. and Mutch, D.G. (1999) Pelvic Radiation with Concurrent Chemotherapy Compared Pelvic and Para-Aortic Radiation for High Risk Cervical Cancer. New England Journal of Medicine, 340, 1137-1143. https://doi.org/10.1056/NEJM199904153401501

[7] Peters, W.A., Liu, P.Y., Barret, R.J., Stock, R.J., Monk, B.J., Berek, J.S., Souhami, L., Grigsby, P., Gordon Jr., W. and Alberts, D.S. (2000) Concurrent Chemotherapy and Pelvic Radiation Therapy Compared Pelvic Radiation Therapy Alone as Adjuvant Therapy after Radical Surgery in High-Risk Early Stage Cancer of Risk. Journal of Clinical Oncology, 18, 1606-1613. https://doi.org/10.1200/JCO.2000.18.8.1606

[8] Whitney, C.W., Sause, W., Bundy, B.N., Malfetano, J.H., Hannigan, E.V., Fowler Jr., W.C., Clarke-Pearson, D.L. and Liao, S.Y. (1999) Randomized Comparison of Fluorouracil Plus Cisplatin Versus Hydroxyurea as an Adjunct to Radiation Therapy in Stage IIB-IVA Carcinoma of the Cervix With Negative Para-Aortic Lymph Nodes: A Gynecologic Oncology Group and Southwest Oncology Group Study. Journal of Clinical Oncology, 17, 1339-1348. https://doi.org/10.1200/JCO.1999.17.5.1339

[9] Spensley, S., Hunter, R.D., Livsey, J.E., Swindell, R. and Davidson, S.E. (2009) Clinical Outcome for Chemoradiotherapy in Carcinoma of the Cervix. Clinical Oncology (Royal College of Radiologists), 21, 49-55. https://doi.org/10.1016/j.clon.2008.10.014

[10] Bonomi, P., Bleesing, J.A., Stehman, F.B., Di Saia, P.J., Walton, L. and Major, F.J. (1985) Randomized Trial of Three Cisplatin Dose Schedules in Squamos-Cell Carcinoma of the Cervix: A Gynecologic Oncology Group Study. Journal of Clinical Oncology, 3, 1079-1085. https://doi.org/10.1200/JCO.1985.3.8.1079

[11] Eifel, P.J., Moughan, J., Owen, J., Katz, A., Mahon, I. and Hanks, G.E. (1999) Patterns of Radiotherapy Practice for Patients with Squamous Carcinoma of the Uterine Cervix: Patterns of Care Study. International Journal of Radiation Oncology ${ }^{\star}$ Biology ${ }^{\star}$ Physics, 43, 351-358. https://doi.org/10.1016/S0360-3016(98)00401-5

[12] Pearsey, R., Brundage, M., Drovin, P., Jeffrey, J., Johnston, D., Lukka, H., MacLean, G., Souhami, L., Stuart, G. and Tu, D. (2002) Phase III Trial Comparing Radical Radiotherapy with and without Cisplatin Chemotherapy in Patients with Advanced Squamous Cell Cancer of the Cervix. Journal of Clinical Oncology, 20, 966-972. https://doi.org/10.1200/JCO.2002.20.4.966c

[13] Green, J.A., Kirwan, J.M., Terney, J.F., Symonds, P., Fresco, L., Collingwood, M. and Williams, C.J. (2001) Survival and Recurrence after Concomitant Chemotherapy and Radiotherapy for Cancer of Uterine Cervix: A Systematic Review and Meta-Analysis. The Lancet, 358, 781-786. https://doi.org/10.1016/S0140-6736(01)05965-7

[14] Stehman, F.B., Bundy, B.N., DiSaia, P.J., Keys, H.M., Larson, J.E. and Fowler, W.C. (1991) Carcinoma of the Cervix Treated with Radiation Therapy. I. A Multi-Variate Analysis of Prognostic Variables in the Gynecologic Oncology Group. Cancer, 67, 2776-2785.

https://doi.org/10.1002/1097-0142(19910601)67:11<2776::AID-CNCR2820671111> 3.0.CO;2-L

[15] Delgado, G., Bundy, B., Zaino, R., Sevin, B.U., Creasman, W.T. and Major, F. (1990) Prospective Surgical-Pathological Study of Disease-Free İnterval in Patients with Stage IB Squamous Cell Carcinoma of the Cervix: A Gynecologic Oncology Group 
Study. Gynecologic Oncology, 38, 352-357.

https://doi.org/10.1016/0090-8258(90)90072-S

[16] Classe, J.M., Rauch, P., Rodier, J.F., Morice, P., Stoeckle, E., Lasry, S. and Houvenaeghel, G. (2006) Surgery after Concurrent Chemoradiotherapy and Brachytherapy for the Treatment of Advanced Cervical Cancer: Morbidity and Outcome: Results of a Multicenter Study of the GCCLCC (Groupe des Chirurgiens de Centre de Lutte Contre le Cancer). Gynecologic Oncology, 102, 523-529. https://doi.org/10.1016/j.ygyno.2006.01.022

[17] Resbeut, M., Cowen, D., Viens, P., et al. (1994) Concomitant Chemoradiation Prior to Surgery in the Treatment of Advanced Cervical Carcinoma. Gynecologic Oncology, 54, 68-75. https://doi.org/10.1006/gyno.1994.1168

[18] Houvenaeghel, G., Buttarelli, M., de Troyer, J., et al. (2006) Surgical Resection after Chemotherapy for Advanced Cervical Carcinoma. Cancer Radiothérapie, 10, 471-476. https://doi.org/10.1016/j.canrad.2006.07.002

[19] Tinga, D.J., Timmer, P.R., Bouma, J. and Aalders, J.G. (1990) Prognostic Significance of Single versus Multiple Lymph Node Metastases in Cervical Carcinoma Stage IB. Gynecologic Oncology, 39, 175-180. https://doi.org/10.1016/0090-8258(90)90428-N

[20] Pilleron, J., Durand, J. and Hamelin, J. (1974) Prognostic Value of Node Metastasis in Cancer of the Uterin Cervix. American Journal of Obstetrics \& Gynecology, 119, 458-462. https://doi.org/10.1016/0002-9378(74)90201-4

[21] Heller, P.B., Malfenato, J.H., Bundy, B.N., Barnhill, D.R. and Okagaki, T. (1990) Clinical-Pathologic Study of Stage IIB, III and IVA Carcinoma of the Cervix: Extended Diagnostic Evaluation for Para-Aortic Node Metastasis-A Gynecologic Oncology Group Study. Gynecologic Oncology, 38, 425-430. https://doi.org/10.1016/0090-8258(90)90085-Y

[22] Rose, P.G. (1994) Localy Advanced Cervical Carcinoma the Role of Chemoradiation. Seminars in Oncology, 21, 47-53. 